\title{
A Mestiçagem Enquanto um Dispositivo de Poder e a Constituição de Nossa Identidade Nacional
}

Resumo: Analisa a questão racial brasileira numa perspectiva foucaultiana. Ao invés de encarar a mestiçagem como um fenômeno natural, isto é, como se fosse o resultado de uma pré-disposição dos portugueses para a mistura étnica, trabalha com a hipótese de que ela é fruto de um dispositivo de poder. Descreve e analisa o desenvolvimento histórico do dispositivo de mestiçagem, demonstrando a participação que a Psicanálise e Arthur Ramos tiveram nele, levanta os problemas que tal dispositivo nos coloca hoje, impondo uma certa racionalidade presente de forma indelével no pensamento racial brasileiro.

Palavras-Chave: Discurso racial brasileiro, dispositivo de mestiçagem, Análise de Discurso, Psicologia e pluralidade étnica.

Abstract: This article intends to analyze the Brazilian racial issue in a foucaultian view. Instead of facing miscegenation as a natural phenomenon, that is, as a result of a Portuguese predisposition to the ethnic mixture, I worked on the supposition that it is a result of a dispositive of power. After describing and analyzing the participation of Psychoanalysis and Arthur Ramos had in it, I raised the problems that he hands us, nowadays, since it imposes us a certain rationality that is present in an indelible way in the Brazilian racial thought.

Emanuel Mariano Tadei

Psicólogo com Licenciatura Plena em Filosofia. Mestre em Psicologia. Professor de Fllosofia no ensino médio desde 1990. Atua na àrea clínica desde 1996

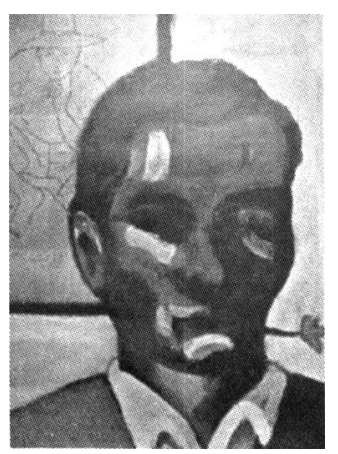
ethnic plurality.

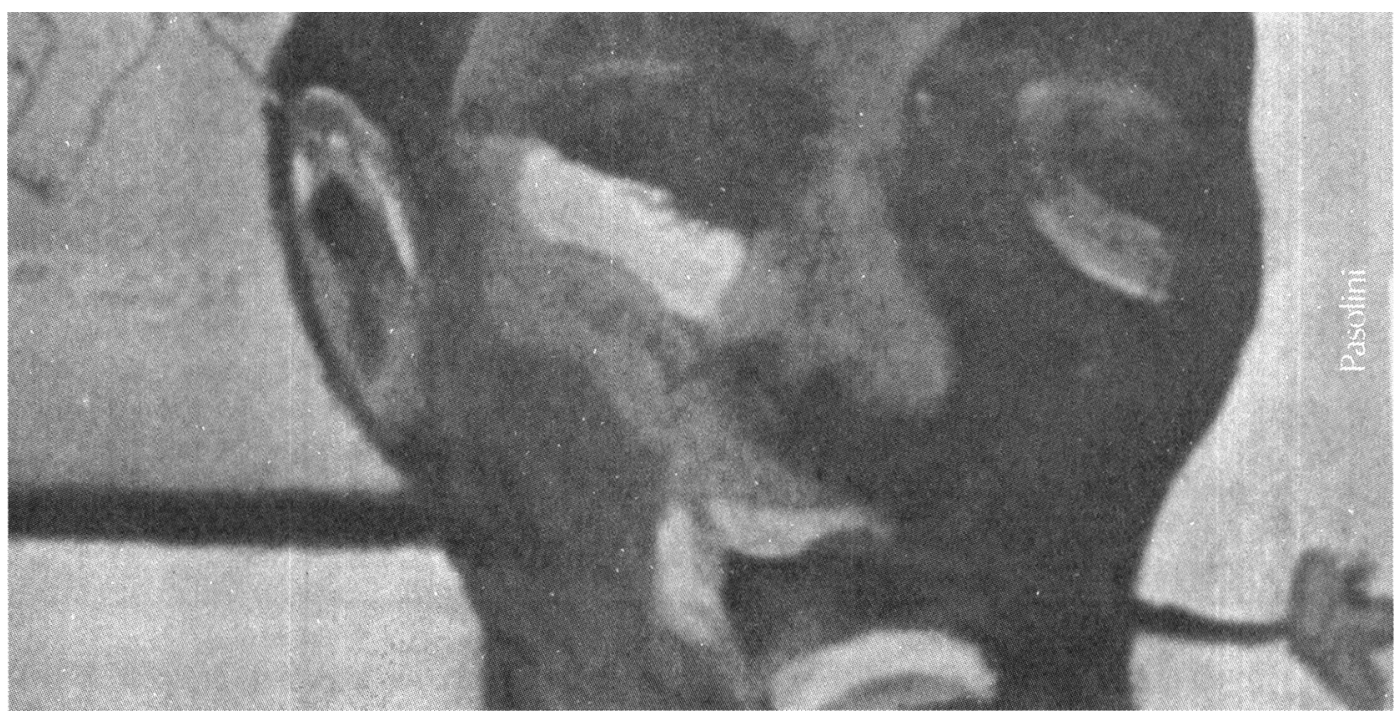

Sempre que o assunto é pluralidade étnica brasileira, acabamos esbarrando na questão da mestiçagem ou miscigenação. Pretendo, com este trabalho, dar uma contribuição no sentido de discutir a mestiçagem não como um fenômeno natural, como esse tema tem sido tratado até o momento no Brasil, e, sim, como um dispositivo de poder. Estarei me apoiando, para tanto, na analítica do poder desenvolvida por Michel Foucault
(Foucault, 1982; 2000). A partir daí, pretendo situar a obra de Arthur Ramos, demonstrando qual é a sua participação nesse dispositivo, bem como o importante papel que nele desempenhou ao fazer uso dos conceitos psicanalíticos para pensar de forma crítica a questão racial brasileira.

Este é um dos grandes desafios do momento para a Psicologia brasileira: contribuir para a superação 
de uma visão ingênua sobre nossos problemas raciais e sobre a constituição de nossa identidade nacional. Mesmo porque a Psicologia e a Psicanálise tiveram e têm ainda uma importante participação naquilo que estou denominando dispositivo de mestiçagem, como tentarei demonstrar ao longo deste trabalho.

A posição assumida por Gilberto Freyre acerca do papel que a miscigenação étnica representou para a colonização portuguesa no Brasil contribuiu para encobrir sua real significação. Gilberto Freyre foi responsável pela divulgação da idéia de "democracia racial". Para ele, os portugueses estariam predispostos por sua própria formação híbrida, fruto da influência histórica que sofreram dos povos muçulmanos (mouros), à miscigenação. Essa influência teria produzido, no seu entender, um afrouxamento dos preconceitos raciais.

Podemos dizer que Gilberto Freyre contribuiu para a naturalização da mestiçagem, ao atribuir sua origem a um fator constitucional que poderia, segundo ele, ser facilmente demonstrado em relação ao colonizador português. Em outras palavras, em vez de discutir e problematizar um pouco mais o conceito de mestiçagem, toma-a como um dado consumado e inquestionável, decorrente de uma pré-disposição dos colonizadores portugueses.

Porém, essa tendência atribuída por Freyre aos portugueses não se aplica aos casos da colonização portuguesa da Índia e da África. Nessas regiões, que apresentaram outras formas de colonização, não ocorreu a mestiçagem como aqui. Se ela fosse uma marca registrada dos colonizadores portugueses, porque não ocorreu também em outras colônias mantidas por Portugal? Isso nos faz pensar que a mestiçagem que ocorreu em larga escala no Brasil deve ser analisada tendo em vista o projeto de colonização aqui desenvolvido pelos portugueses.

Isso nos habilita a encarar a mestiçagem não mais como algo natural, mas sim como um dispositivo de poder. Estou chamando de dispositivo um tipo de formação que, em determinado momento histórico, tem como função principal responder a uma urgência. Parafraseando Foucault, podemos dizer que o dispositivo pode se manifestar como programa de uma instituição ou, ao contrário, como elemento que permite justificar e mascarar uma prática que permanece muda até então. Pode ainda funcionar como reinterpretação dessa prática, dando-lhe acesso a um novo campo de racionalidade.

Na condição de dispositivo de poder, o dispositivo de mestiçagem envolve um conjunto heterogêneo de elementos: discursos, açōes, leis e programas de instituições. De forma mais específica, ele pode ser entendido como um conjunto de saberes e de estratégias de poder que atua sobre nossa identidade nacional, tendo por objetivo integrar e tornar dóceis as etnias que estão na raiz de nossa nacionalidade (no caso os indígenas do continente e os negros africanos). É o dispositivo de mestiçagem que dirige e comanda as ações e saberes numa determinada direção, com a intenção de atingir seu objetivo final: criar uma consistência entre todos esses elementos díspares, gerando subjetividades dóceis, mal delimitadas e manipuláveis.

Além disso, esse dispositivo acabou por instaurar uma certa racionalidade em nosso país, à medida que passou a funcionar como uma estrutura elementar presente em tudo o que tem sido produzido sobre nosso país e nossa identidade nacional em termos discursivos. Ele se traduz por uma estrutura discursiva elementar que determina nossa forma de pensar e falar sobre o Brasil e sobre o problema racial brasileiro.

Entendo por racionalidade as condições que determinam a produção de conhecimento (o ver e o falar), a partir das quais são construídos objetos e enunciados acerca de uma dada problemática. Ela pode ser facilmente localizável e passível de datação, pois se constitui como uma estrutura discursiva elementar, isso é, como um conjunto de regras de formação que organizam os vários enunciados, objetos e sujeitos, formando classes de enunciados de níveis distintos de enunciação, mas que obedecem a uma determinação comum de ordem mais geral.

Como localizar esse dispositivo e seus efeitos? Temos de buscar nos estratos, isto é, nas camadas arqueológicas, os enunciados que permitirāo estabelecer essa rede discursiva, bem como as estratégias de poder que compōem esse dispositivo.

Sua gênese e desenvolvimento apresentou três etapas: do século XVII à meados do século XIX tivemos a emergência de um saber sobre a mestiçagem no meio religioso, que depois se disseminou entre a população colonial, sendo acolhido pelos intelectuais e políticos brasileiros do período em questão (esse saber era favorável à miscigenação); em seguida, na segunda metade do século XIX e nas primeiras décadas do século $X X$, esse saber sofreu uma epistemologização, isto é, ganhou um estatuto científico, passando a ser uma preocupação constante dos cientistas brasileiros (os vários cientistas brasileiros que abordaram esse assunto, nesse momento, apresentaram uma resistência à miscigenação), e, a partir da década de 1930, ele sofre uma reinterpretação, momento em que os principais 
estudiosos brasileiros do assunto passaram a destacar os aspectos positivos da mestiçagem, momento em que se consolida a idéia de democracia racial.

Nosso ponto de partida é um provérbio recolhido pelo jesuíta Antonil, no século XVII. Diz ele que:

“O Brasil é o inferno dos negros, purgatório dos brancos e paraíso dos mulatos" (citado em Ramos, 1962, p. 46).

Esse provérbio traz em si um enunciado importante: o mestiço se destaca como o mais adaptado e preparado para enfrentar as condições de vida nos trópicos. Esse enunciado dá ao mestiço uma certa visibilidade em relação às outras etnias. Essa era a idéia que circulava entre a população da colônia já no século XVII.

Gilberto Freyre nos dá outra pista importante sobre a gênese do dispositivo de mestiçagem em Sobrados e Mucambos. Ele menciona algumas experiências realizadas pelos monges beneditinos, que estudaram os resultados do cruzamento de raças. Vejamos o que ele nos diz:

\section{"O Brasil é o inferno dos negros, purgatório dos brancos e paraíso} dos mulatos".

Ramos
"Esta não foi, entretanto, a observação dos Beneditinos, frades argutos que, no Brasil, andaram sempre a fazer experiências de genética com os seus escravos para chegarem à conclusão, no século XVIII, de que os melhores, os mais dotados de inteligência e de talento, eram os mulatos (...)" (Freyre, 1951, pp. 1001-1002).

Novamente o mestiço é tomado como uma saída para os problemas que a vida nos trópicos suscitava. São destacadas duas qualidades importantes: a inteligência e o talento. Provavelmente isso está relacionado às possibilidades de aprender e de colocar em prática no trabalho o fruto desse aprendizado. Seria um avanço em relação ao trabalho escravo indígena e africano. Os beneditinos, portanto, com um olhar arguto, perceberam que estava aí a saída para o problema da mão-de-obra, uma vez que eles eram proprietários de engenhos.

Os jesuítas também deram uma contribuição para a formação de um saber sobre a mestiçagem. Vejamos um comentário de um historiador sobre as idéias do Pe. Vieira em relação à mestiçagem. Não podemos nos esquecer de que o Pe. Vieira era descendente de africanos por parte de sua avó.

“(...) Na teologia colonial, em Vieira, por exemplo, a mestiçagem é comparada a um purgatório entre o mundo negro (entregue às forças do mal) e o mundo branco dos cristãos. Uma espécie de 'paedagogia ad Christum' (Clemente de Alexandria).
Aliás, o sincretismo entre as formas 'pagãs' (africanas, indígenas) e as formas 'cristãs' (leia-se européias) também é interpretado assim, de forma pedagógica, como estádio intermediário entre o mal e o bem, entre o pecado e a virtude" (Hoornaert, 1993, p. 27).

A idéia de mestiçagem que é defendida pela Igreja por volta do século XVIII está subordinada a um plano de moralização. Esse enunciado sobre a mestiçagem assume um patamar diferente daqueles discutidos anteriormente: aqui ela serviria para purgar moralmente as raças consideradas atrasadas e pagãs. $\mathrm{O}$ mestiço estaria num estágio moral intermediário entre o bem e o mal, entre o pecado e a virtude. Assim, a Igreja obteria um gradiente que vai do mal ao bem, com estágios intermediários.

Porém, mesmo sendo diferentes, esses enunciados guardam alguns pontos comuns entre si: o destaque dado ao mestiço. Através deles, notamos como o mestiço foi-se tornando um objeto de preocupação e de conhecimento, através da visibilidade que passou a ter, seja como mais adaptado às condições de vida nos trópicos, seja como mão-de-obra passível de ser mais qualificada, ou como estágio intermediário entre o bem e o mal. Esses três enunciados nos remetem a três problemas distintos: as duras condições de vida nos trópicos, a questão do potencial humano (para aprender e trabalhar) e o problema moral. Eles são enunciados a partir de posições distintas de sujeito: do ponto de vista de um mercantilista, considerando que Antonil era um legítimo representante da visão mercantilista; do ponto de vista dos beneditinos, possuidores de engenhos $\mathrm{e}$ que buscavam uma melhoria da mão-de-obra disponível; e dos jesuítas, interessados na moralização da colônia. Embora distintos, esses enunciados se acumularam em sua materialidade, dando origem a um saber sobre a mestiçagem.

Enfocando um outro problema, isto é, o problema do controle sobre o grande contingente de escravos, contingente esse superior ao de homens brancos, os administradores, políticos e intelectuais irão discutir a miscigenação num plano distinto dos anteriores. Nesse momento (final do século XVIII e início do século XIX), a mestiçagem será discutida com a finalidade de solucionar um problema que sempre incomodou os brancos europeus no Brasil Colônia: o medo constante de revoltas por parte dos escravos. Esse pavor foi comum durante todo o período colonial pelo fato de não existir um nexo social capaz de tornar dóceis os escravos, tanto indígenas como negros africanos. Ele vai se evidenciar quando o assunto passa a ser a Independência do Brasil. Vejamos a passagem seguinte: 
"Foi assim, de pavor a atitude de grande parte de brancos - principalmente europeus - no Brasil da época em que se processou a independência política da até então colônia portuguesa. Consideravam alguns impossível essa independência se não se cuidasse de conseguir, contra o elemento africano, a proteção de uma potência européia, ou de assegurar-se, no novo Estado, a preponderância do elemento europeu. No desenvolvimento de novo elemento que não fosse nem africano nem europeu mas a combinação dos dois e de mais um terceiro, o indígena - numa palavra, o mestiço -, é que estava, porventura, a solução, aliás entrevista não só pelos homens de gênio de José Bonifácio como pelo bom-senso dos simples Soares Franco. Solução para a qual vinham, aliás, concorrendo desde remotos anos a política social da Metrópole e a da própria lgreja, com exceção, talvez, dos Jesuítas. A esse respeito são significativas ocorrências como aquelas que se encontram em velhos cronistas do Brasil colonial" (Freyre, 1951, p. 1009-1010).

Podemos destacar mais um enunciado de mestiçagem na passagem acima. Agora a função atribuída à mestiçagem está na possibilidade de domesticar o caráter agressivo e insubordinado do negro africano. A mestiçagem como elemento capaz de criar um nexo social entre as várias raças que compunham nossa população.

Francisco Soares Franco, em seu ensaio sobre os Melhoramentos de Portugal e do Brasil, também tomava a mestiçagem como uma saída para esse problema:

"Do assunto já se ocupara Francisco Soares Franco em Ensaio sobre os Melhoramentos de Portugal e do Brasil, publicado em 1821, onde reconhecera: 'A casta preta he hoje a dominante no Brazil', isto é, dominante pelo número. Daí sua sugestão para que se estimulasse a mestiçagem e se favorecesse o mestiço, desenvolvendo-se a emigração de europeus e proibindo-se a importação de negros. Os brancos substituíram os negros nas cidades marítimas, já no serviço doméstico, enquanto os pretos se concentrariam nos sertões nos trabalhos de minas e plantaçōes. Apelava para o legislador no sentido de que os mestiços não pudessem legalmente casar senāo com indivíduos de 'casta branca ou índia', promovendo-se assim o 'baldeamento' dos mestiços na 'raça branca'. (...)" (Freyre, 1951, p. 1008-1009).

Aqui é colocado o problema da imigração. A imigração de brancos europeus para o Brasil, que começou a se intensificar por volta de 1847, está dentro dessa estratégia mais ampla, além de ser encarada também como uma forma de resolver o problema da falta de mão-de-obra escrava. Assim sendo, a imigração atende ao interesse econômico, e contribui para acelerar a euro-peização do Brasil, esparramando a cor branca pelo nosso território. Aqueles que eram favoráveis à política imigrantista também tinham em mente a melhoria de nossa imagem diante dos olhares de viajantes estrangeiros que por aqui passaram. Havia um certo horror aos costumes africanos. $E$ temos de observar que a ação do Estado aqui foi importante.

Em meados do século XIX, vai ser travada uma discussão acirrada entre os vários partidários no terreno da política imigrantista, discussão essa que foi registrada pela imprensa da época. Os interesses dos fazendeiros, chocavam-se com os interesses do Império. Para os fazendeiros os trabalhadores imigrantes poderiam ser de qualquer raça e lugar. Os representantes legais do Império não pensavam do mesmo modo.

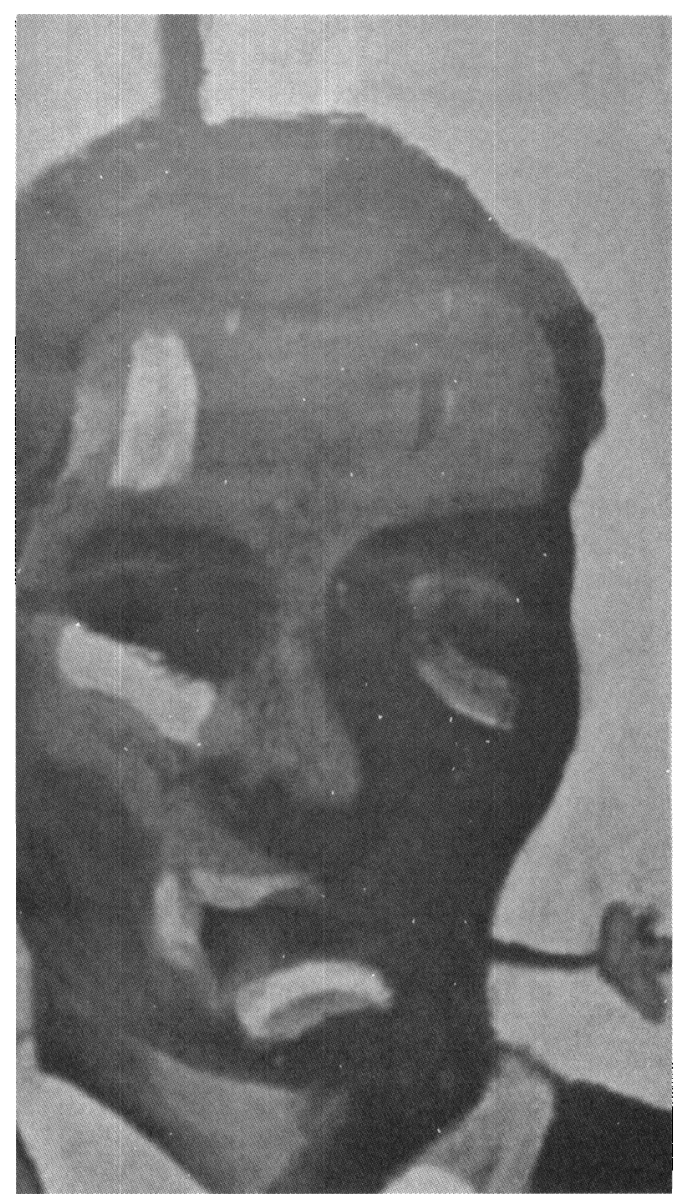

"(...) Na teologia colonial, em Vieira, por exemplo, a mestiçagemé comparada a um purgatório entre o mundo negro (entregue às forças do malle e mundo branco dos cristãos. Uma espécle de 'paedagogia ad Christum' (Clemente de Alexandria). Aliás, o sincretismo entre as formas 'pagãs' (africanas, indígenas) e as formas 'cristãs' (leia-se européias) tambémé interpretado assim de forma pedagógica, como estádio intermediário entre o mal eo bem, entre o pecado e a virtude".

Hoornaert

"Determinados a consolidar a grande propriedade e a agricultura de exportação, os fazendeiros e o grande comércio buscavam angariar proletários de qualquer parte do mundo, de qualquer raça, para substituir, nas fazendas, os escravos mortos, fugidos e os que deixavam de vir da África. Preocupados, 
ao contrário, com o mapa social e cultural do país, a burocracia imperial e a intelectualidade tentavam fazer da imigração um instrumento de 'civilização', a qual, na época, referia-se ao embranquecimento do país. Desde logo, as duas correntes encaravam de maneira radicalmente distinta a ação do Estado e a política imigrantista" (Alencastro \& Renaux, 1997, p. 293).

Estava em jogo, portanto, o destino da nossa nacionalidade. A questão do trabalho apontava outro problema: que sociedade resultará da imigração?

"A questão do trabalho desembocava em cheio na questão nacional, no projeto sobre o conjunto de famílias, de vidas privadas, que formaria a futura vida pública brasileira: no reverso do debate sobre a imigração desenhava-se o debate sobre a nacionalidade. Repare-se ainda que essas discussōes transcorriam em tempos de unificação dos Estados nacionais europeus, numa época em que a homogeneidade cultural, lingüística, comunitária apresentava-se como um trunfo indispensável para viabilizar as nações modernas.

Desse modo, o antagonismo entre os interesses dos fazendeiros e da burocracia imperial pela imigração reportava-se tanto ao presente quanto ao futuro do Império: qual povo virá? que sociedade resultará?" (Alencastro \& Renaux, 1997, pp. 294-295).

Foi nessa época também que a forma como contamos nossa História, no caso a história oficial de nosso país, foi estabelecida. Segundo Lilia Moritz Schwarcz, em seu livro O Espetáculo das Raças, em 1844 foi promovido um concurso pelo Instituto Histórico e Geográfico Brasileiro, que premiaria o melhor projeto sobre "Como escrever a História do Brasil". O projeto vitorioso foi de Karl Friedrich Philipp von Martius, naturalista alemão e sócio correspondente do Instituto, cuja tese se centrava na especificidade da trajetória deste país tropical.

"Qualquer que se encarregue de escrever a História do Brasil, país que tanto promete, jamais deverá perder de vista quais os elementos que ali concorrerão para o desenvolvimento do homem. São esses porém de natureza muito diversa, tendo convergido de um modo muito particular as três raças... (...)" (Citado em Schwarcz, 1998, p. 112).

Daí em diante, essa será a fórmula adotada pelos historiadores que se debruçaram sobre nossa História. Evidentemente, não foi esse autor que estabeleceu isso. Podemos dizer que o que ele propõe é fruto da racionalidade imposta pelo próprio dispositivo de mestiçagem. Isso é, ele foi influenciado pela racionalidade estabelecida por esse dispositivo.
Vejamos a citação seguinte:

"O projeto vencedor propunha, portanto, uma 'fórmula', uma maneira de entender o Brasil. A idéia era correlacionar o desenvolvimento do país com o aperfeiçoamento específico das três raças que o compunham. Estas, por sua vez, segundo Von Martius, possuíam características absolutamente variadas. Ao branco, cabia representar o papel de elemento civilizador. Ao índio, era necessário restituir sua dignidade original ajudando-o a galgar os degraus da civilizaçāo. Ao negro, por fim, restava o espaço da detração, uma vez que era entendido como fator de impedimento ao progresso da nação: 'Não há duvida que o Brasil teria tido', diz Von Matius, 'uma evolução muito diferente sem a introdução dos míseros escravos negros'" (Citado em Schwarcz, 1998, p. 112).

Poderíamos dizer que os enunciados expostos neste texto repetem vários dos enunciados de mestiçagem descritos e analisados anteriormente, ou seja, Von Matius não está sendo original ao enunciar isso. A racionalidade imposta pelo dispositivo de mestiçagem é compartilhada por Von Matius.

O dispositivo de mestiçagem é a rede que pode ser estabelecida entre essas várias ações, discursos e medidas legais discutidas até aqui. Podemos dizer que, em meados do século XIX, a mestiçagem era um saber disseminado entre os membros da Igreja, nos órgãos do governo metropolitano, além de ter sido apropriada por ałguns intelectuais ligados ao poder instituído no Império. Entretanto, ela só vai ganhar o estatuto de um conceito científico alguns anos mais tarde, mais exatamente no final do século $X I X$, quando esse saber sofreu um processo de epistemologização.

Em O Espetáculo das Raças, Schwarcz aborda exatamente o período no qual isso aconteceu. Ela o situa entre 1870 e 1930, quando a mestiçagem ou a questão racial no Brasil é amplamente discutida em quatro instituições distintas: pelos cientistas dos museus de Ciências Naturais, pelos bacharéis das faculdades de Direito, pelos médicos das faculdades de Medicina e pelos intelectuais dos institutos históricos e geográficos espalhados por todo o Brasil.

Não podemos deixar de observar, no entanto, que pelo fato de ter situado o discurso racial brasileiro num tempo e num espaço bem delimitados, isto é, no momento em que ele passou por um processo de epistemologização, Lilia Moriz Schwarcz nos dá a impressão de que encara o discurso racial brasileiro como algo que já cumpriu seu papel. Ela reconstrói essa história para compreender 
nossos dilemas raciais atuais. Por não levar em consideração o saber anterior a esse discurso racial de cunho científico, e por não encará-lo, como nós, como parte de um dispositivo que o engloba, atuante até hoje, ela atribui o fato de escrevermos nossa História partindo das três raças a esse concurso promovido pelo Instituto Geográfico e Histórico. $\mathrm{Na}$ verdade, desde o século XVII vinha-se constituindo um saber sobre a mestiçagem nos meios religioso, político e intelectual, como estamos tentando demonstrar aqui.

Ela reconstrói com muita precisão os discursos sobre os problemas raciais no Brasil. Nesse momento, discute-se tanto a miscigenação como seus possiveis efeitos em nossa sociedade. Destacam-se as seguintes instituições e intelectuais: do Museu Nacional, localizado no Rio de Janeiro, o antropólogo Roquete Pinto; da Faculdade de Direito de Recife, a chamada Escola de Recife, tendo à frente dois grandes intelectuais, Tobias Barreto e Silvio Romero; entre os médicos baianos Nina Rodrigues e seus seguidores, e entre os intelectuais dos Institutos Históricos e Geográficos, Oliveira Viana e Euclides da Cunha.

Segundo Schwarcz, nesse período de nossa história:

"Raça é um dado científico e comparativo para os museus; transforma-se em fala oficial nos institutos históricos de finais do século; é um conceito que define a particularidade da nação para os homens de lei; um índice tenebroso na visão dos médicos. O que se percebe é como em determinados contextos reelaboram-se símbolos disponíveis dando-lhes uso original. Se a diferença já existia, é nesse momento que é adjetivada" (Schwarcz, 1998, p. 242).

A base teórica para toda essa discussão é o darwinismo social e o evolucionismo, ambos trazidos da Europa. Aqui temos de fazer uma advertência àqueles que vêem no discurso racial brasileiro apenas uma mera cópia das teorias formuladas na Europa, como se essa presença não passasse de um modismo passageiro. Pelo exposto até aqui, verificamos que o discurso racial brasileiro tem raízes profundas nos problemas enfrentados pelo Brasil, no que diz respeito a um projeto de modernização e constituição de uma identidade nacional. Ele é anterior ao seu momento de epistemologização.

No momento em que a mestiçagem ganha um estatuto científico, apresentará uma resistência à mistura racial, isto é, a maior parte dos médicos, juristas, antropólogos e estudiosos do assunto começaram a enfatizar os aspectos negativos da miscigenação.
Porém, essa resistência em nada prejudicou o avanço desse dispositivo. A partir da década de 1930, em oposição a essa visão negativa a respeito da mestiçagem, surgiram várias obras, como as produzidas por Arthur Ramos, Gilberto Freyre e Jorge Amado, por exemplo, em campos distintos do saber. No entanto, esses autores, ao se colocarem na defesa da mestiçagem, contribuíram para a propagação do próprio dispositivo de mestiçagem. Eles reinterpretaram todo o dispositivo de mestiçagem em novas bases conceituais.

A grande contribuição dada por Gilberto Freyre e Arthur Ramos está no deslocamento da questão do âmbito puramente racial/biológico para o plano cultural, atacando o conjunto miscigenaçãodegeneração-perversão. E isso só foi possível graças às influências que ambos sofreram tanto da Antropologia Cultural como da Psicanálise.

“(...) Com Gilberto Freyre e Jorge Amado, surge uma interpretação paradisíaca da mestiçagem como 'confraternização das raças', 'laboratório da humanidade de amanhã', 'democracia racial'. A própria mestiçagem seria uma superação dos graves contrastes sociais, econômicos e políticos vividos no Brasil. (...)" (Hoornaert, 1993, p. 27).

Influenciado pela Antropologia Cultural e pela Psicanálise, Gilberto Freyre valorizou a sexualidade como elemento capaz de promover a integração entre as três raças: o branco europeu, os indígenas do continente e os negros africanos. $O$ produto dessa confraternização era o mestiço. Constatamos, então, que na obra de Gilberto Freyre a figura do mulato voltou a ganhar o centro das atençōes. Em Sobrados e Mucambos, ele dedica um capítulo inteiro tentando nos convencer de que ninguém estava mais preparado para ascender socialmente no século XIX do que o mulato. A partir das primeiras décadas do século $X X$, o mulato e a mulata serão plenamente idealizados em todos os setores de nossa vida cultural.

E onde Gilberto Freyre encontrou dados para promover essa inversão no dispositivo de mestiçagem? Recuperando os saberes produzidos nos séculos XVII e XVIII, quando a mestiçagem era um assunto importante, disseminado em vários setores da sociedade colonial. Naquele momento, a mestiçagem não era tomada como algo negativo, mas sim como a solução para nossos problemas sociais.

A obra do psiquiatra baiano Arthur Ramos pode ser encarada como mais um exemplo claro de como a Psicanálise foi aplicada na compreensão de nossos dilemas raciais. Em linhas gerais, podemos dizer que ele abordou as questões afrobrasileiras através da elaboração de uma psicologia
"Raça é um dado científicoe comparativo para os museus; transformase em fala oficial nos institutos históricos de finais do século; é um concelto que define a particularidade da nação para os homens de lei; um índice tenebroso na visão dos médicos. O que se percebe é comoem determinados contextos reelaboram-se simbolos disponivels dando-Ihes uso original. Se a diferença já existia, é nesse momento que é adjetivada".

Schwarcz

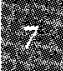


"De toda maneira, ao contrário de outras nações, onde o passado escrovocrata sempre lembrou violência e arbítrio, no Brasil a história foi reconstruída de forma posittva, mesmo encontrando pouco respaldo nos dadose documentos pregressos. (...)".

Schwarcz social amparada em alguns conceitos freudianos e em alguns conceitos extraídos da Antropologia Cultural, além é claro do pensamento de Jung.

Em seu livro Introdução à Antropologia Brasileira, Arthur Ramos faz uma revisão bibliográfica das obras produzidas no Brasil sobre as questões do negro e do índio. Ele não se limita a apresentar as várias obras sobre o assunto, fazendo ainda uma análise crítica das mesmas. Trata-se de um verdadeiro inventário do pensamento racial brasileiro até aquele momento.

O ponto central desse livro está na distinção estabelecida por Arthur Ramos entre as noções de raça e cultura. Segundo o autor, o pensamento racial brasileiro estava repleto de preconceitos, pois não fazia essa distinção. Muitos problemas atribuídos aos negros em termos raciais não passavam de problemas culturais. Essa distinção permitiu a Arthur Ramos levantar e denunciar os vários preconceitos contra os negros.

Contrariando a tese do branqueamento defendida por Roquete Pinto, que enfatizava o desaparecimento da raça negra no País, ele vai encontrar a presença do negro em nossa cultura em lugares dos quais ninguém suspeitava. Enquanto Roquete Pinto está voltado para a aparência, isto é, a cor da pele (o biológico), Arthur Ramos está voltado para as manifestações mais profundas da vida cultural e mental do negro presentes em larga escala nas várias produções culturais brasileiras.

Podemos mencionar ainda a importante influência dos conceitos psicanalíticos no projeto modernista de 1922. Como é do conhecimento de todos, os modernistas de 22 se apropriaram dos conceitos psicanalíticos para criar uma visão antropológica do homem brasileiro: o "antropófago civilizado".

Depois desse rápido percurso, em que foram discutidos a gênese e o desenvolvimento do dispositivo de mestiçagem, temos de levantar uma questão: quais foram as conseqüências e os resultados produzidos pela ação do dispositivo de mestiçagem? Em sua investigação sobre os problemas raciais brasileiros, Lilia Moritz Schwarcz faz uma observação importantíssima:

“De toda maneira, ao contrário de outras nações, onde o passado escravocrata sempre lembrou violência e arbítrio, no Brasil a história foi reconstruída de forma positiva, mesmo encontrando pouco respaldo nos dados e documentos pregressos. (...)" (Schwarcz, 1998, p. 188).

Não podemos encarar isso como um dos efeitos das estratégias de poder que estamos analisando? Como técnica de sujeição:
“(..) Se o mito deixou de ser oficial, está internalizado. Perdeu seu estatuto científico, porém ganhou o senso comum e o cotidiano" (Schwarcz, 1998, p. 241).

Se o dispositivo de mestiçagem parece não estar mais na ordem do dia, não é porque ele perdeu a razão de ser. Muito pelo contrário, ele cumpriu sua missão. Continua a autora:

“(...) No Brasil convivem sim duas realidades diversas: de um lado, a descoberta de um país profundamente mestiçado em suas crenças e costumes; de outro, o local de um racismo invisivel e de uma hierarquia arraigada na intimidade. (...)" (Schwarcz, 1998, p. 241).

O livro Raizes do Brasil, de Sérgio Buarque de Holanda, publicado em 1936, também nos fornece alguns indícios a respeito dos efeitos gerados pela ação do dispositivo de mestiçagem. Estudando a personalidade étnica brasileira, ele criou a expressão "homem cordial". Por "homem cordial" ele se refere à lhaneza no trato, à hospitalidade, à generosidade, que definem alguns dos principais traços do caráter do brasileiro. Mas ele faz uma correção logo em seguida: seria engano supor que essas virtudes possam significar "boas maneiras" ou civilidade. São antes de tudo expressões legítimas de um fundo emotivo extremamente rico e transbordante. Nenhum povo está mais distante de uma vida ritualista, como acontece com os japoneses, do que os brasileiros. Temos um desejo de estabelecer intimidade. Nosso convívio social é regido por uma "ética emotiva".

Ele destaca também a falta de coesão de nossa vida íntima, que não é bastante disciplinada para envolver toda a personalidade, integrando-a como peça consciente, no conjunto social. Como resultado dessa falta de coesão e disciplina interior, destaca-se a facilidade do brasileiro em assimilar todo tipo de idéia e gestos, mesmo contraditórios ente si, sem maiores dificuldades.

Retomando o que foi dito, Lilia Moritz Schwarcz e Sérgio Buarque de Holanda destacaram dois aspectos importantes que constatamos ainda hoje na subjetividade do brasileiro: um preconceito internalizado aliado a uma subjetividade mal delimitada e pouco coesa. Levanto a hipótese de que isso é fruto da ação do dispositivo de mestiçagem. E nesse aspecto, precisamos definir melhor, depois do caminho percorrido até aqui, o que entendemos por esse dispositivo.

O dispositivo de mestiçagem apresenta as seguintes características: ele incita à mistura étnica; coloca a sexualidade num plano estratégico, ou seja, como o veículo capaz de promover a confraternização 
das etnias; dilui a identidade nacional, ao apostar num amálgama capaz de unir os vários elementos que compōem nossa nacionalidade, porém, manobra essa identidade em construção para determinadas direções, conforme a conjuntura de cada período de nossa História; coloca-nos numa busca insistente pela nossa identidade nacional, impedindo um envolvimento maior com a própria nacionalidade por parte dos brasileiros; ele é, ainda, produtor de subjetividades dóceis e maldelimitadas, uma vez que promove a mistura étnica apagando as origens, apagando o passado e suas contradições, voltando-se para o futuro e deshistorizando as raízes históricas individuais $\mathrm{e}$ nacionais.

A partir da discussão de vários aspectos do dispositivo de mestiçagem, levantamos uma questão importante: teria esse dispositivo se esgotado, perdendo sua funçāo a partir de meados do século $X X$ ?

Acredito que, a partir de meados do século $X X$, esse dispositivo sofreu uma metamorfose importante, mas sem desaparecer. Ele foi reinterpretado em outras bases. Fica mais fácil constatar isso na década de 1970, quando os brasileiros experimentaram a crise mais aguda de identidade nacional. Antes, a mestiçagem era discutida num plano étnico (a união entre os brancos europeus, negros africanos e indigenas do continente). A partir de meados do século XX, a questão subjetiva vai ganhar o centro das discussões, sendo que o embate aí se dará entre dois pólos distintos: o nacional e o estrangeiro.

Houve uma coincidência entre essa metamorfose e a difusão do lacanismo no Brasil na década de 1970. A Tropicália, o Cinema Novo e a Poesia Concreta criaram as condições para o lacanismo se difundir em nosso país, ao lado dos embates entre as associações psicanalíticas brasileiras ligadas à IPA (International Psychoanalytical Association) e àqueles que tiveram seu ingresso impedido às mesmas.

Num primeiro momento, MDMagno e Betty Millan saíram na busca de uma psicanálise brasileira, ao mesmo tempo em que perseguiram de forma insistente as especificidades subjetivas dos brasileiros. Num segundo momento, Contardo Calligaris e Octavio Souza também entraram nesse debate, tentando desvendar a subjetividade do brasileiro por meio dos conceitos psicanalíticos. Todos eles são psicanalistas lacanianos. A Psicanálise parecia estar retomando as suas origens no Brasil, assimilada como uma antropologia capaz de contribuir para a solução de nossos problemas raciais.

Nesse contexto, as questões ligadas aos negros e índios foram deixadas de lado, ficando como pano de fundo. Todos os esforços se voltaram para o diagnóstico de nossos dilemas subjetivos. O Brasil era, assim, colocado no divā da Psicanálise. As obras produzidas por psicanalistas ou por intelectuais que aplicaram conceitos psicanalíticos para pensar a questão dos negros nas décadas de 1920 e 30 simplesmente caíram no esquecimento. E isso é um reflexo do avanço da cultura individualista entre nós, fato que acompanhou o processo de industrialização e urbanização de nosso país.

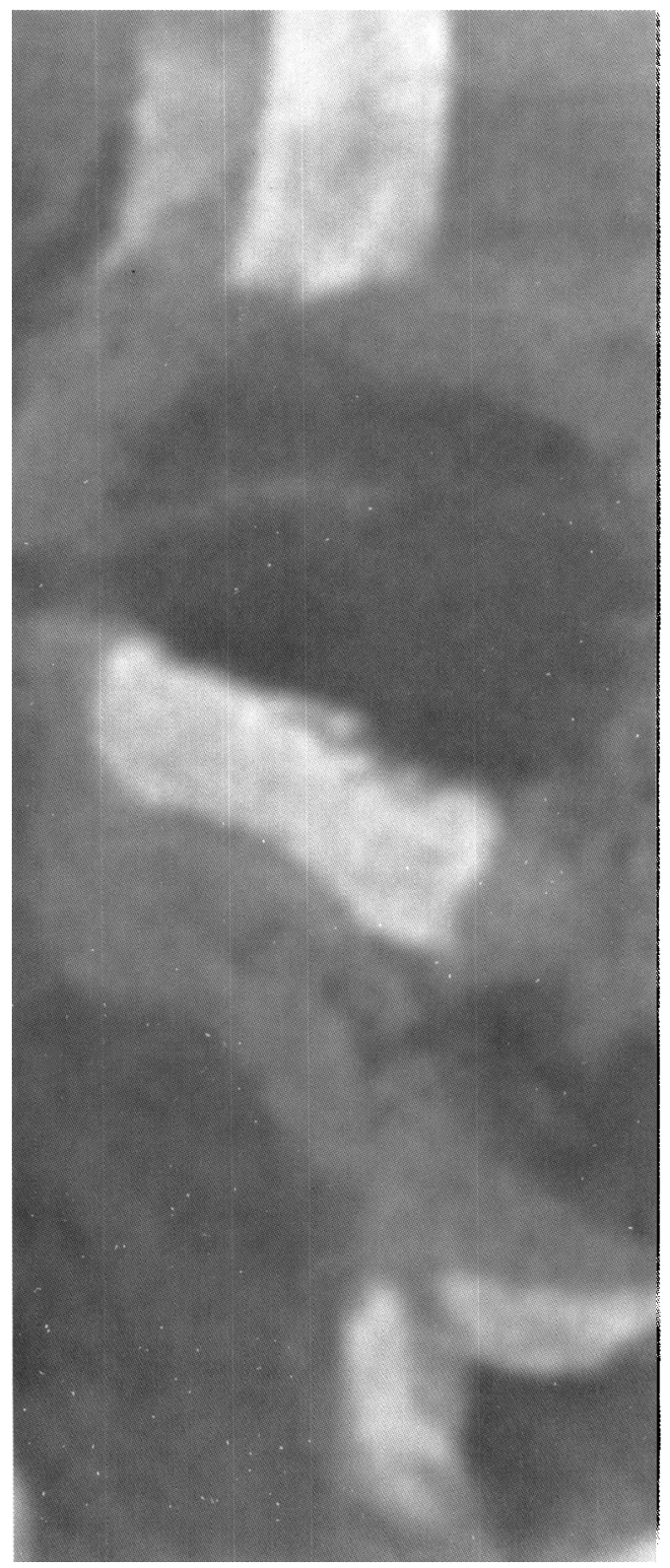

"(...) No Brasil convivem sim duas realidades diversas: de um lado, a descoberta de um país profundamente mestiçado em suas crenças e costumes: de outro, o local de um racismo invisivele de uma hierarquia arraigada na intimidade. (...)"

Schwarcz

Antes, o negro e seus costumes eram o alvo das preocupações dos cientistas e intelectuais brasileiros. Seus costumes, como o batuque e a 
capoeira, eram considerados primitivos demais e envergonhavam nosso país diante dos olhares estrangeiros. Na década de 1970, não é mais isso que nos incomoda. O negro de certa forma estava "integrado" à sociedade brasileira. A cultura negra foi obrigada a se fundir com vários elementos da cultura européia. $O$ problema agora está ligado a alguns traços culturais e subjetivos que precisavam ser combatidos, por serem considerados arcaicos e incompatíveis com a modernização do País.

Isso ficará mais claro ao analisarmos as obras de dois dos autores apontados mais acima: Contardo Calligaris e Octavio Souza. Para Calligaris, nossa constante busca por uma identidade nacional e os constantes apelos que fazemos aos estrangeiros por um reconhecimento, estariam diretamente relacionados a uma insuficiência da função paterna no Brasil. A partir daí ele explica também a dificuldade do brasileiro de assujeitamento à lei e a falta de um significante nacional.

"No Brasil, o que me encanta ò minha volta é que a maioria dos brosileiros tem uma genealogia totalmente cruzada, múltipla, complexa. extremamente rica, e que, em seus corpos vivos há muito tempo, eles atenuaram os conflitos de hoje".

Michel Serres

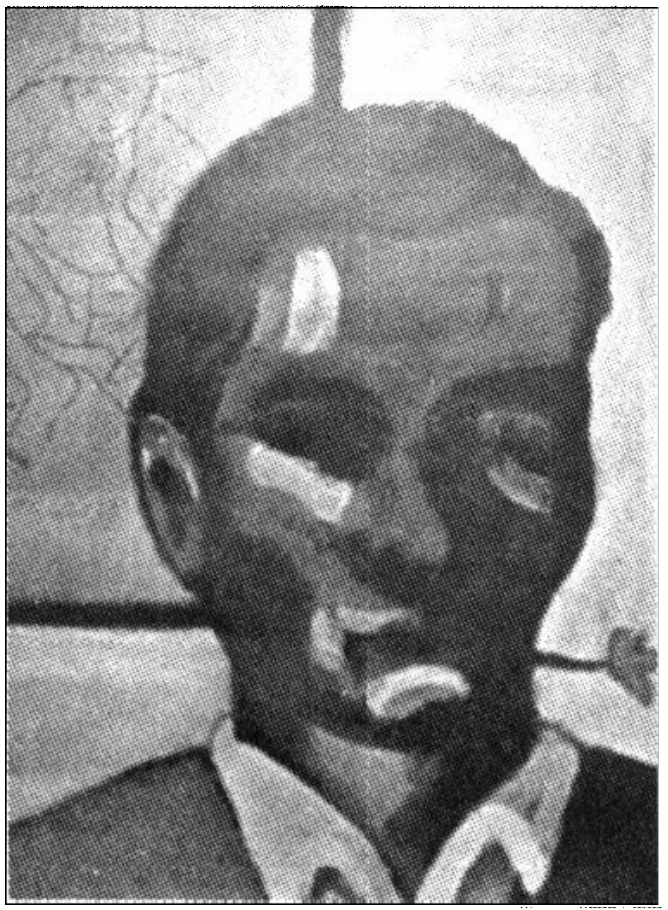

Nos últimos capítulos de seu livro, Calligaris apresenta de forma sutil aquilo que poderia ser uma solução para nossa inconsistência identitária. Segundo ele, seria importante refazer os elos simbólicos que unem os dois lados do oceano - o Brasil e suas origens européias. A busca por nossos antepassados revelaria nossa descendência européia, fruto da miscigenação, que ocorreu em larga escala em nosso país. Mas, e os negros e os índios? Ele não dá a essa questão o peso que ela mereceria, porque para ele o problema está na oposição entre as posições subjetivas de colonizador e de colonizado, encontrada na subjetividade do brasileiro. Quer dizer, o brasileiro pode falar de si tanto na posiçāo de colonizado, como na posição de colonizador. Em ambos os casos, experimentamos um dano simbólico que torna impossível a busca por um significante nacional

É por isso que afirmo que as análises de Calligaris estão dentro da lógica do dispositivo de mestiçagem. Ao tentar desvendar aquilo que nos afasta da modernização tão almejada, ele propõe a busca de nossas origens européias. Só que isso conduz a um apagamento de nosso passado negro e indígena.

Em Octavio Souza, encontramos um alerta sobre a exaltação do exotismo que, segundo ele, tem sido recorrente entre aqueles que buscaram desesperadamente um significante nacional. A aposta no exótico, como uma forma de responder ao mandato utópico dirigido a nós pelos colonizadores, que desde o início da colonização se impressionaram com nossas diferenças, nos coloca numa posição delicada. Essa identificação que a demanda dos colonizadores nos faz buscar um significante nacional exótico, através do qual queremos afirmar nossa diferença. Porém, adverte Octavio Souza, isso pode despertar tanto o encantamento como a xenofobia por parte dos estrangeiros.

A crítica ao exotismo acaba reatualizando um desacordo em relação a alguns traços peculiares existentes em nossa cultura, que é tão diversificada e diferente da cultura européia, como aconteceu anteriormente. Isto é, assim como a cultura negra foi alvo de ataques por parte daqueles que queriam modernizar o Brasil a qualquer custo, introduzindo nosso país na lista dos países desenvolvidos, esse alerta de Octavio Souza aponta para aspectos de nossa subjetividade que deveriam ser abandonados pelos riscos de nos afastar dessa modernidade que ainda estamos buscando. A exaltação do exótico existente em nosso país poderia se voltar contra nós.

Contardo Calligaris e Octavio Souza, ao fazerem uma crítica psicanalítica do Brasil, não conseguiram desvendar aquilo que é essencial: o dispositivo de mestiçagem. No meu entender, ficaram presos à fenomenologia desse dispositivo e acabaram interpretando o mesmo de forma um tanto quanto questionável. O que eles descrevem é correto, mas é apenas a exterioridade do dispositivo de mestiçagem, ou seja, seus efeitos. Quero dizer com isso que não é uma dificuldade de assujeitameto à lei que nos faz dirigir sempre um apelo ao estrangeiro, como no caso da histérica que sempre está à procura de um pai. $\mathrm{O}$ nosso 
vazio identitário é agenciado por várias estratégias de poder, que o direcionam para determinados pontos que interessam ao projeto de país que está em jogo em cada momento de nossa História, isto é, o vazio identitário é um produto do dispositivo de mestiçagem, que por sua vez é agenciado com o intento de manipular nossa identidade nacional, que está ainda sempre por se fazer. São os efeitos provocados por essa ação que criam a percepção de uma dificuldade de assujeitamento à lei.

Nessa mesma linha de investigaçăo, um grupo de psicanalistas lacanianos de vários países, reunidos na França, mais especificamente na Association Freudienne Internationale e na Maison de I'Amérique Latine, tentaram desvendar aspectos da subjetividade dos povos latino-americanos a partir dos conceitos psicanalíticos.

"Nós nos propusemos a precisar os diferentes modos de colonização e também a incidência da escravidão, a importância da imigração e situar, se possivel, as conseqüências atuais desses fatores na organização social e econômica, nas instituiçōes e na subjetividade" (Association Freudienne Internationale e Maison de l'Amérique Latine, 2000, p.23).

Esses esforços resultaram na defesa de uma hipótese bastante inusitada, da existência de um inconsciente pós-colonial entre os povos da América Latina. Da mesma forma que, com a teoria da dependência econômica formulada na década de 1970 por Fernando Henrique e seus colaboradores, foi explicado nosso subdesenvolvimento econômico, agora, com essa hipótese de um inconsciente póscolonial, estão tentando explicar nossos dilemas subjetivos e nossos sintomas sociais.

Trata-se, evidentemente, de uma psicologização da questão. $E$ isso era previsível desde o início, dada a presença dessa racionalidade que estamos problematizando aqui. Se com MDMagno e Betty Milan teve início a busca por uma psicanálise brasileira, agora ganhamos um inconsciente póscolonial. Através das contribuições da Psicanálise, bastante difundida nos vários setores de nossa vida cultual, construímos uma explicação para nossos dilemas que procuram interiorizar o nosso sentimento de inferioridade por vivermos num país subdesenvolvido, como tendo uma causa em fatores psicológicos. Sem mudar esses aspectos subjetivos, continuaríamos vítimas de nossas mazelas sociais.

É importante observar também que o dispositivo de mestiçagem tem sido alvo de um interesse internacional, mais especificamente entre os intelectuais franceses. Eles parecem ter vislumbrado a possibilidade de usar esse dispositivo, tão bem sucedido no Brasil, para resolver seus problemas locais. A Europa atualmente tem sofrido muito com os problemas raciais, num momento em que está em plena discussão a integração dos vários países (Mercado Comum Europeu). É nesse contexto que devemos inserir a obra de Michel Serres Filosofia Mestiça. Ele, com certeza, um pensador bem intencionado, vê no caso particular do Brasil um modelo que poderia ser adotado para solucionar os problemas europeus e mundiais.

Em sua participaçăo no programa Roda Viva, da TV Cultura, exibido em 08/11/1999, quando veio ao Brasil para participar do Congresso Internacional do Desenvolvimento Humano, realizado pela Universidade São Marcos, ele tocou nesse assunto. Não podemos nos esquecer de que Michel Serres lecionou em 1973 na Universidade de São Paulo e, portanto, já tinha um certo conhecimento sobre o Brasil.

Foi perguntado a ele:

"O senhor chegou a pensar e escrever sobre o Brasil. Sobre esse grande caldeirão de raças que é o Brasil. O que isso é bom ou ruim para o Brasil (esse caldeirão de raças)?"

Em sua resposta, Michel Serres apontou os problemas que a globalização tem trazido recentemente, pois ela cria uma porosidade entre as fronteiras, afetando as pessoas. Além, disso, ele menciona o problema das guerras mundiais, que tanto preocupam a humanidade. Em seguida, ele diz que:

"No Brasil, o que me encanta à minha volta é que a maioria dos brasileiros tem uma genealogia totalmente cruzada, múltipla, complexa, extremamente rica, e que, em seus corpos vivos há muito tempo, eles atenuaram os conflitos de hoje. Escrevi um livro, muito mais tarde, que chamei ' $\mathrm{O}$ Terceiro Instruído' e foi traduzido por um belo título em português onde aparece o adjetivo 'mestiço' [Filosofia Mestiça]. E, nesse livro, eu dizia que todo processo de conhecimento é uma mestiçagem. Porque, quando falamos outra língua, e lamento muito não falar o português, temos um outro corpo. Quando pensamos em outra ciência, entramos em outro ser humano. $E$, de tanto falar línguas diferentes, de tanto conhecer disciplinas diferentes, fabricamos em nós um mestiço. E há, no conhecimento mestiço, uma espécie de paz entre as disciplinas, uma espécie de armistício entre as oposiçōes do saber. É uma imagem intelectual do que aconteceu na vida real no Brasil. Vocês conseguiram tantas mestiçagens entre todas as populações do mundo porque, no Brasil, o mundo inteiro está representado: asiáticos, europeus, americanos, nativos da América, do Hemisfério Sul, 
etc. Portanto, vocês conseguiram tão bem, na paz, este tipo de mestiçagem, que creio que deveriam ter consciência de que têm o modelo das soluções requeridas hoje pelas guerras mundiais."

A mestiçagem, tão criticada em outros tempos, por ter sido considerada a principal causa de nossas mazelas sociais agora é promovida a fator capaz de promover a paz e a harmonia entre os vários povos e nações.

Gostaria de concluir minha exposição retomando a questão dos desafios que a Psicologia brasileira tem de enfrentar: precisamos romper com essa lógica que procurei descrever até aqui. Temos de analisar o pensamento racial brasileiro a partir de outras referências que não a racionalidade imposta pelo dispositivo de mestiçagem. Para tanto, precisamos de mais investigações, que, como essa, procurem desmontar esse dispositivo de mestiçagem fazendo uma crítica à racionalidade que ele nos impõe. Só assim poderemos pensar mais além do dispositivo de mestiçagem.

A Psicologia e a Psicanálise tiveram e ainda têm uma participação importante no desenvolvimento desse dispositivo. Por essa razão, é de se esperar que os psicólogos e psicanalistas façam a desmontagem desse dispositivo, abrindo caminho para o aparecimento de novas formas de abordagens da questão racial brasileira, superando assim os vários mitos que ainda estão disseminados em nossa sociedade.
Esses mitos têm obstruído a produção de estudos psicológicos sobre os problemas raciais brasileiros. É como se não fosse preciso estudar esse assunto, já que ele "não" se constitui num problema importante. Num trabalho recente, intitulado Afrodescendente: identidade em construção, o psicólogo Ricardo Franklin demonstrou que a produção psicológica sobre o assunto ainda é bastante incipiente. Os negros, da mesma forma que sofrem uma marginalização em vários setores de nossa vida social, como era de se esperar, também ocupam um lugar marginal na produção psicológica brasileira.

Os problemas identitários enfrentados pelos negos e afros-descendentes são inúmeros. Muito tem se falado sobre os problemas identitários dos imigrantes, aos quais é atribuído o sucesso da Psicanálise em nosso país, já que eles teriam encontrado nela uma forma de superação dos mesmos. Esse é o caso, por exemplo, de Luís Cláudio Figueiredo, que defende essa idéia em seu livro Modos de Subjetivação no Brasil. E os negros e afros-descendentes? Não teriam eles também se constituído numa possível clientela para a Psicanálise e para a Psicologia? Por que ficaram à margem dessas duas ciências, se eles também apresentam problemas identitários, a exemplo dos imigrantes?

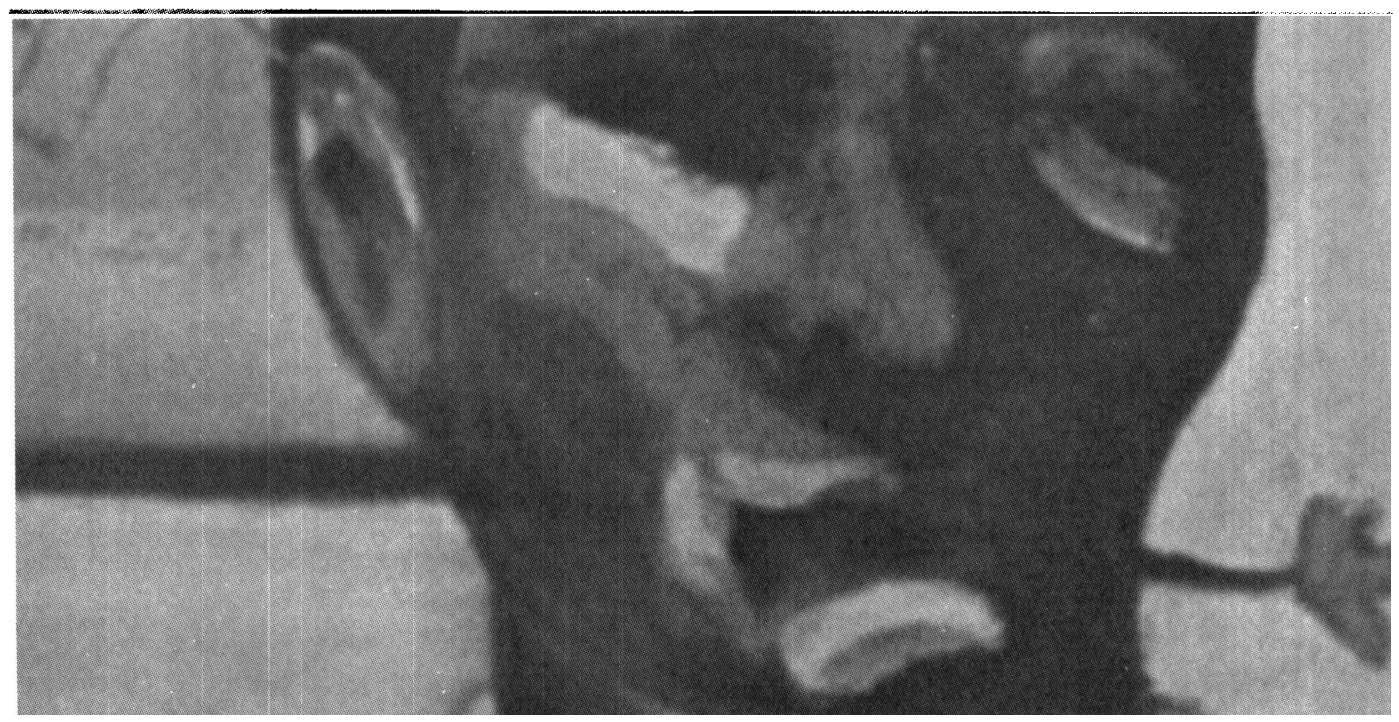


Emanuel Mariano Tadei Av. Integraçāo, 1735, Apt. 338, Cohab V, Carapicuiba /SP. CEP 06327-290 Tel.: (11) 4187-2361

E-mail:marianot.alp@zaz.com.br

Alencastro, L. F.e Renaux, M.H. (1997). Caras e modos dos migrantese imigrantes. Em Luis Felipe de Alencastro (Org.), Historia da Vida Privada no Brasil (pp. 291-335). São Paulo, Companhia das Letras, vol. 2.

Association Freudienne Internationale (2000). Um inconsciente póscolonial, se é que ele existe. Porto Alegre, Artes e Oficios.

Buarque de Holanda, S. (1986). Raízes do Brasil. 18a edição, Rio de Janeiro, José Olympio Editora.

Calligaris, C. (2000). Hello Brasil! - notas de um psicanalista europeu viajando pelo Brasil. 6 a edição, São Paulo, Ed. Escuta.

Ferrera, R. F. (2000). Afro-descendente: identidade em construção. São Paulo: EDUC; Rio de Janeiro: Pallas.

Foucault, M.(1982). Microfísica do poder. $3^{\text {a }}$ edição, Rio de Janeiro, Edições Graal.

(2000). Arqueologia do Saber. 6ª ediçăo, Rio de Janeiro, Forense Universitária.

Freyre, G. (1951). Sobrados e Mucambos. 2ª edição, São Paulo, Livraria José Olympio Editora.

Hoornaert, E. (1993). A questão do corpo nos documentos da primeira evangelizaçáo. Em Maria Luiza Marcílio (Org.), Família, mulher, sexualidade e Igreja na História do Brasil (pp. 11-27). Sāo Paulo, Ediçōes Loyola.
Ramos, A. (1962). Introdução à Antropologia Brasileira: Os Contatos Raciais e Culturais. $3^{a}$ edição, Rio de Janeiro, Livraria-Editora da Casa do Estudante do Brasil, vol. 3 .

Serres, M.(1997). Filosofia mestiça. São Paulo, Nova Fronteira.

Souza, O. (1994). Fantasias de Brasil. As identificaçōes em busca da identidade nacional. Sāo Paulo, Ed. Escuta.

Schwarcz, Lilia Moritz (1998). O espetáculo das raças: cientistas, instituiçóes e questāo racial no Brasil (1870-1930). São Paulo, Cia das Letras.

(1998). Nem preto nem branco, muito pelo contrário: cor e raça na intimidade. Em Lilia Moritz Schwarcz (Org.), História da vida privada no Brasil: constrastes da intimidade contemporânea (pp. 173244). São Paulo, Companhia das Letras, vol. 4.

Tadei, E. M. (2002). Uma arqueologia da psicanálise no Brasil. Dissertação de Mestrado. Universidade São Marcos, São Paulo.

Michel Serres. Programa Roda Viva. TV Cultura - Fundação Padre Anchieta. São Paulo, 1999.

\section{Referências}

bibliográficas 